\title{
Characterisation of Microscopic Changes in Macroscopically Unaffected Peritoneum in Women with and without Endometriosis
}

\author{
Mira Luhmann, Vito Chiantera, Jalid Sehouli and Sylvia Mechsner* \\ Endometriosis Centre Charité, Department of Gynaecology, Charité, Campus Virchow Clinic, Berlin, Germany \\ *Corresponding author: Sylvia Mechsner, Endometriosis Centre Charité, Department of Gynaecology, Charité, Campus Virchow Clinic, Berlin, Germany
}

Received: February 23, 2021; Accepted: March 03, 2021; Published: March 29, 2021

\begin{abstract}
Study question: Is there a difference in the occurrence of occult microscopic endometriotic lesions in normal peritoneum between women with and without endometriosis and if so are there other differences in the structure of the peritoneum between these groups?

Introduction: Occult Microscopically Endometriosis (OME) was firstly described by Murphy et al. in 1986. Since then there has been more research on the topic but without finding any conclusions about the clinical significance. Therefore, OME could be a physiological phenomenon that occurs in women with and without endometriosis (EM) or it could also be an early stage of real EM lesions.

Methods: For this study, we surgically removed the macroscopically unaffected peritoenum from the left and/or right paracolic gutter from 64 women with and 22 women without EM. The tissue was then immunohistochemically stained with antibodies of an Estrogen Receptor Alpha (ERa), a Progesterone Receptor (PR), Cytokeratin, CD10, and Anti-Smooth Muscle Cell Actin (ASMA).

Results: OME lesions were found in five of the 86 patients (5, 81\%). One of these lesions was found in a woman without EM which is $4,5 \%$ of the control group. In the group of women with EM, there were four patients with OME lesions which is $6,3 \%$ of the cohort, so there was no statistically significant difference between these groups. Besides the OME lesions, there were immune cells found in the tissue of 12 women with EM (18, $8 \%$ of the EM cohort) but none in the control group. These findings did not correlate with the OME lesions.
\end{abstract}

\section{Introduction}

EM is one of the most common gynecological diseases and affects approximately $10 \%$ of women of a reproductive age $[1,2]$. It is defined as the presence of endometrial and/or stromal cells outside the uterine cavity and is most likely to be found disseminated on the peritoneum of the pelvic cavity like in the pouch of Douglas, on the sacrouterine ligaments, in the ovaries and the ovarian fossae [3-5]. Typical symptoms are dysmenorrhea, cyclical and acyclical pelvic pain, and infertility [6]. As the intensity of symptoms does not correlate with extending of infestation it often takes several years until the diagnosis is made [7-9]. Today's gold standard to detect peritoneal EM is by laparoscopy [10-12]. But within this technique small EM lesions may be overlooked.

As the pathogenesis of EM has not been clarified and probably cannot be described by only one theory, we were wondering which part of the OME lesions take it in. We chose to concentrate on the impact of the peritoneal fluid, which is known to have several spaces in the peritoneal cavity where it is more present. One of these spaces is the right paracolic gutter, which is why we decided to examine the difference between the right and left paracolic gutters for the occurrence of OME $[13,14]$. OME was first described in 1986 by
Murphy et al. [15]. It is defined by the presence of endometriosis in macroscopically normal-looking tissue. Even though there have been further studies, the meaning of OME is still unclear. Firstly, it could have an important status in the pathogenesis of endometriosis. Secondly, it could also be a physiological phenomenon with no disease value. To find out more about the clinical relevance of OME we histologically examined tissue specimens derived from visually normal peritoneum of the paracolic gutters of women with and without EM to detect the possible occurrence of OME. Due to the fact, that endometriotic lesions are associated with the local inflammatory response we also investigated the occurrence of IC and angiogenesis in this tissue.

\section{Materials and Methods}

\section{Subjects}

During the period between 2013 and 2016, peritoneal biopsy samples from 64 women with visible endometriosis and 22 women without visible endometriosis were collected during laparoscopy. The institute of pathology made the diagnostic assurance by histological examination. The most common reason for the operations in women with EM was EM resection. For women without EM, it was resection of fibroids. With the knowledge of the influence the peritoneal fluid has 
on the distribution of EM lesions, we chose to collect tissue from the right and left paracolic gutters. The goal was to see if the distribution of OME lesions is also influenced by it. All biopsy specimens were collected in accordance with the patients and were approved by the guidelines of the ethics committee. In Table 1 you can find the clinical profiles of the two groups.

\begin{tabular}{|l|c|c|c|}
\multicolumn{1}{|c}{ Table 1: Subjects. } \\
\hline & & With EM n (\%) & Without EM n (\%) \\
\hline Number & & 64 & 22 \\
\hline Age & Mean Range & 29,9 years 18-47 & 36,4 years 18-50 \\
\hline Oral Contraceptives (OC) & & $24(37,5)$ & $4(18,2)$ \\
\hline & Menstruation & $7(10,9)$ & $0(0)$ \\
& Proliferation & $6(9,4)$ & $3(13,64)$ \\
Menstrual cycle & Secretion & $14(21,9)$ & $3(13,64)$ \\
& No Cycle (due to OC) & $24(37,5)$ & $4(18,18)$ \\
& Unknown & $13(20,3)$ & $12(54,54)$ \\
\hline \multirow{3}{*}{ Coexisting diseases } & Adenomyosis (AM) & $43(67,2)$ & $0(0)$ \\
& Myoma (UM) & $9(14,1)$ & $12(54,5)$ \\
& Sterility & $10(15,6)$ & $1(4,5)$ \\
& Hypothyroidism & $8(12,5)$ & $4(18,2)$ \\
\hline
\end{tabular}

\section{Antibodies}

We performed immunohistochemical studies to investigate immunoreaction of target antigens in the serial sections of biopsies using the following antibodies: PR (Progesterone receptor), ERa (Estrogen receptor alpha), CD 10 (stromal cell marker), ASMA (AntiSmooth Muscle Cell Actin), and Cytokeratin (glandular cell marker). Non-immune mouse immunoglobulin ( $\operatorname{IgG}$ ) antibody was used as a negative control. The detailed names, dilutions, and manufacturers are given in Table 2.

Table 2: Antibodies

\begin{tabular}{|l|c|c|}
\hline Name of antibody & Dilution & Manufacturer \\
\hline Ms anti- Progesteron-R Dako PgR & $1: 50$ & Dako, Denmark \\
\hline Ms anti-ER-alpha 1D5 & $1: 60$ & Dako, Denmark \\
\hline Ms ASMA abcam 1A4 & $1: 50$ & Abcam, UK \\
\hline Ms anti-CD10 ab951 & $1: 50$ & Dako, Denmark \\
\hline Anti-Cytokeratin MNF116 Dako & $1: 50$ & Dako, Denmark \\
\hline Biotin-SP-conjugated AddiniPure Rabbit Anti-Mouse IgG & $1: 400$ & Dianova, USA \\
\hline
\end{tabular}
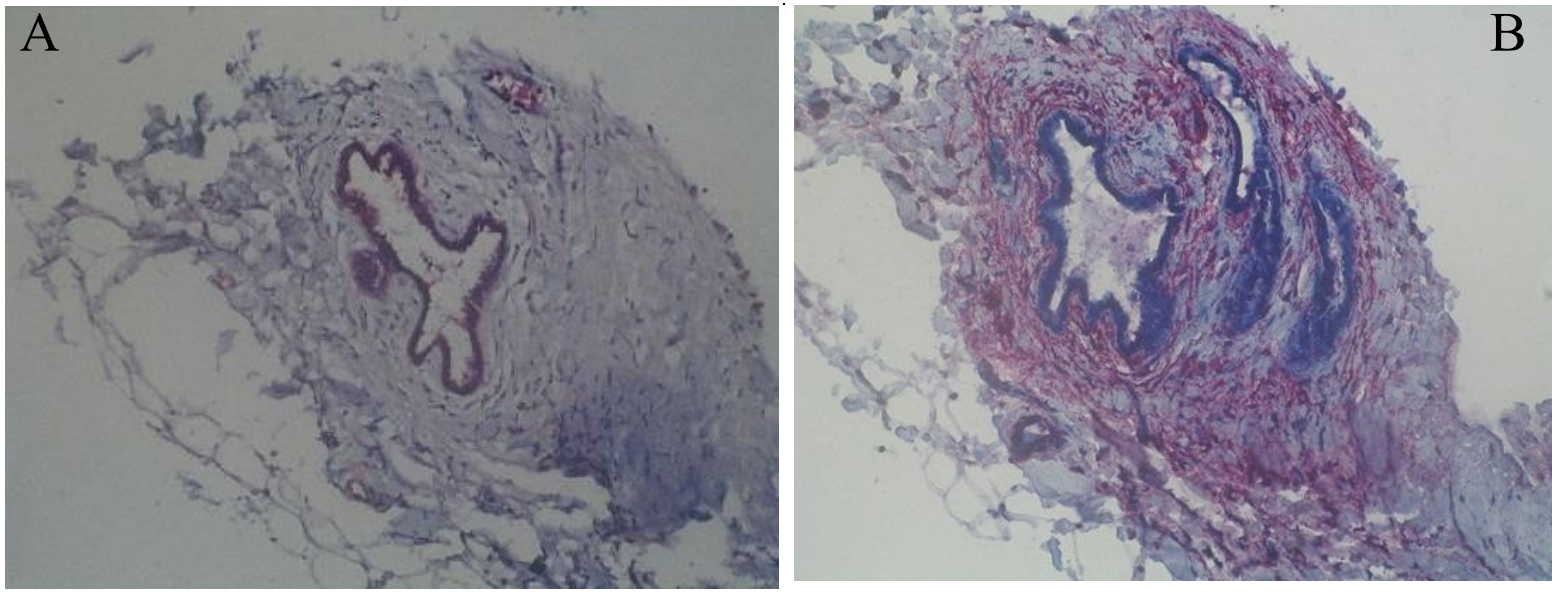

Figure 1: OME lesion 03, which contains all three parts of an EM lesion. A: Cytokeratin; B: ASMA. 
a p-value of 0.768 and therefore shows no statistical relevance of the probability of occurrence of OME between the two groups of patients.

Table 3: Summary of OME lesions.

\begin{tabular}{|l|c|c|c|c|c|}
\hline OME lesion & 01 & 02 & 03 & 04 & 05 \\
\hline Glandular cells & Yes & Yes & Yes & No & No \\
\hline Stromal cells & No & No & Yes & Yes & Yes \\
\hline SMCs & Yes & Yes & Yes & No & No \\
\hline Size in $\boldsymbol{\mu m}$ & $88 \times 30$ & $328 \times 75$ & $310 \times 312$ & $222 \times 62$ & $337 \times 140$ \\
\hline
\end{tabular}

Table 4: Clinical profiles of patients with OME.

\begin{tabular}{|l|c|c|c|c|c|}
\hline OME lesion & 01 & 02 & 03 & 04 & 05 \\
\hline EM & No & Yes & Yes & Yes & Yes \\
\hline Menstrual cycle & Proliferative & Menstruation & Unknown & Proliferative & No Cycle \\
\hline OC & No & No & No & No & Yes \\
\hline Age (years) & 45 & 38 & 45 & 36 & 25 \\
\hline History & UM & AM, Sterility & AM & AM, UM & AM \\
\hline Side & Right & Right & Right & Right & Left \\
\hline Cell type in OME & $\begin{array}{c}\text { Glandular } \\
\text { cells }\end{array}$ & $\begin{array}{c}\text { Glandular } \\
\text { cells }\end{array}$ & $\begin{array}{c}\text { Glandular } \\
\text { cells }\end{array}$ & $\begin{array}{c}\text { Stromal } \\
\text { cells }\end{array}$ & $\begin{array}{c}\text { Stromal } \\
\text { cells }\end{array}$ \\
\hline
\end{tabular}

\section{The Occurrence of Immune Cells in Peritoneal Tissue}

Besides the OME lesions, we also detected some groups of immune cells. These cells were seen in the immunostaining pattern of CD10. In total there were 12 patients who had such groups (containing lymphocytes and granulocytes) in their peritoneal tissue. All of these patients were in the EM group and no inflammatory signs could be found in the control group. In the group of women with EM there were $18,8 \%$ demonstrably affected by inflammation of the peritoneum. The p-value of 0.029 , determined using a chi-square test, shows the statistical relevance of this result.

\section{The Occurrence of Blood Vessels in Peritoneal Tissue}

To find out if the process of neoangiogenesis takes part in the development of OME we examined all tissue specimens for blood vessels. To take into account the difference in the size of the samples, the vessel density was determined using the hot-spot method.

In women with EM we found a slightly higher density than in women without $\mathrm{EM}(1,74$ vessels per $\mathrm{mm} 2$ in women with $\mathrm{EM}$ versus 1.66 vessels per $\mathrm{mm} 2$ in women without $\mathrm{EM})$. However, this difference is with a p-value of 0.519 determined using a Mann-Whitney $\mathrm{U}$ test not statistically relevant.

\section{Discussion}

There has been more research done on this topic since Murphy et al. first described the occurrence of OME lesions in 1986. Synoptically this has all but confirmed the presence of OME. However, in the study of Redwine and Yokom, it was the other way around and they found OME to be more common in women without EM. It is important to point out that this study only used a small control group consisting of 10 women, which limits the meaningfulness of it [16-22]. Nevertheless, there has not been a statistical significance in the occurrence of OME between women with and without EM in any of the studies. Table 5 shows a summary of all the studies about OME.

Even though there is no significant difference between the occurrence rate of OME in this study compared to Nisolle, Balasch, and Kahn, et al. there are reasons why they found a higher rate. First of all the technical possibilities were significantly improved in the last few years. Furthermore and more interestingly, we examined tissue from the paracolic gutters, which is not known to be one of the most common sites for EM. In contrast, all the other authors decided to take tissues from sites of the peritoneum where EM is very likely to find in the pelvis $[6,13,23]$.

\section{The Meaning of OME}

There are two potential meanings of OME. Firstly, it could be an early stage of a "real" EM lesion. In that case, it would be involved in the development and eventually even in the persistence and recurrence of EM after a successful treatment. Secondly, it could also be a physiological phenomenon in which endometrial cells settle in the peritoneum but later get broken down by the immune system. In that case, it would not have anything to do with the development of a "real" EM lesion.

The first case could explain why up to $50 \%$ of patients who underwent surgical EM resection, have a recurrence of complaints and "new" EM lesions within 5 years [24,25]. The opinion of Kahn et al. that OME lesions are biologically active and have growth potential would support this theory [22].

On the other hand, the fact that the prevalence of OME in women with and without EM is almost the same suggests that OME lesions have no influence on the development of EM or only in connection with other influencing factors that have not yet been finally clarified.

Table 5: Summary of results of studies about OME [16-22]

\begin{tabular}{|l|c|c|c|c|}
\hline Study & Year & Operation & Localization of removed tissue & $\begin{array}{c}\text { Frequency of OME in } \\
\text { patients without EM }\end{array}$ \\
\hline Murphy et al. & 1986 & Laparotomie & Cul-de-sac & - \\
\hline Redwine & 1988 & Laparoscopy & Posterior pelvic peritoneum & $25 \%$ \\
\hline Redwine, Yocom & 1990 & Laparoscopy & $\begin{array}{c}\text { Cul-de-sac, Sacrouterine ligaments, Broad } \\
\text { ligaments }\end{array}$ & $0 \%$ \\
\hline Nisolle et al. & 1990 & Laparoscopy & Sacrouterine ligaments & $10 \%$ \\
\hline Nezhat et al. & 1991 & Laparoscopy & Peritoneum, 3-5 cm next to EM lesions & $15 \%$ (clin. diagnosis) vs. 3,9\% (histolog. diagnosis) \\
\hline Balasch et al. & 1996 & Laparoscopy & Sacrouterine ligaments & $13 \%$ \\
\hline Kahn et al. & 2014 & Laparoscopy & $\begin{array}{c}\text { Pouch of Douglas, Uterovesicle space, } \\
\text { Sacrouterine ligaments }\end{array}$ & $6 \%$ \\
\hline
\end{tabular}




\section{Distribution of OME Lesions}

The peritoneal fluid has a typical distribution in the peritoneal cavity. Due to the force of gravity, it is usually located in deeper locations such as the Pouch of Douglas. However, negative intracranial pressures during inspiration and the influence of peristalsis regularly lead to a cranial flow of the peritoneal fluid. Therefore, the fluid runs over the paracolic gutters. The majority of the peritoneal fluid runs over the right paracolic gutter, as it is deeper than the left paracolic gutter. In this way, the fluid reaches the subdiaphragmatic space on the right side and from there is directed back into the deeper areas via the inframesocolic compartment. This circulation of the PF in the peritoneal cavity results in four places where it is particularly frequent/ long $[13,26]$. As one of these places is the right paracolic gutter, we decided to examine both of the paracolic gutters to see if there is a difference in the occurrence of OME lesions. In this study the lesions were distributed in a 4: 1 ratio (right: left) in the paracolic gutters. This result suggests that the development of the lesions is justified or at least encouraged by the influence of the peritoneal fluid, their composition, and their flow directions [13,14,27]. Therefore, one could either support Sampson's theory or say that retrograde menstruation causes endometrial cells to enter the PF and adhere to the peritoneum as they circulate, and assume that growth factors, angiogenesis factors, and inflammatory factors contained in the PF promote the development of OME lesions [27-29].

\section{Immune Cells}

Interestingly, when comparing the specimens in the paracolic gutters of women with and without EM, it became clear that immune cells were only found in tissue samples from patients with EM. The associations of immune cells could be an expression of the inflammatory response in the context of EM and OME lesions that have been eliminated by the immune system. However, since they tended to be found more often on the left side and OME lesions as well as normal EM lesions are mainly located in the right paracolic gutter, it can be assumed that there are inflammatory processes in the entire peritoneal tissue of women with EM. A study by Scheerer et al. from 2016 also found a significantly more frequent occurrence of immune cells in the peritoneal tissue of women with endometriosis compared to women without endometriosis [30].

The question of whether the peritoneum becomes flammable through the EM, or whether the peritoneum is more likely to develop EM lesions due to its inflammatory consideration is still open. However, five women with inflammatory tissue were under the influence of $\mathrm{OC}$ at the time of surgery. This medication can prevent the progression of EM lesions and improve the symptoms. However, this is not the case for all patients who take OC, and often after the pills have been discontinued the symptoms recur quickly [31,32]. This could be because the peritoneum is less penetrated by EM lesions, but it is still affected by inflammatory processes and may therefore promote the formation or regrowth of regressed lesions.

\section{Amount of Blood Vessels}

The pathogenesis of EM is known to be influenced by VEGF [33]. The growth factor leads to an increased blood flow to the tissue permeated by EM and thereby promotes the progression of the lesions [34]. In this study, there was no statistically relevant difference in the vascular density between women with and without EM. Furthermore, no relevantly increased vessel density could be found in the tissue pieces in which there were OME lesions. Therefore, they did not seem to be associated with neoangiogenesis. In contrast to the samples with OME lesions, however, an increased vascular density was found in samples with immune cells, which corresponds to a typical inflammatory reaction.

\section{Conclusion}

In this study, a few cases of OME were detected in both women with and without EM. There was no significant difference in the frequency of occurrence between the two cohorts. An important significant difference in the peritoneal tissue of women with EM compared to that of women without EM was the appearance of immune cells, which were only found in women with EM. Both lymphocytes and granulocytes were found, which, however, were in no case associated with an OME lesion in this study. These tissue samples also had an increased average number of vessels, which can be easily reconciled with an inflammatory reaction. Even though this result was not significant, it does show a certain trend.

As OME occurs in both tissue samples from women with and tissue samples from women without EM, it is likely that it is a physiological phenomenon in which endometrial cells settle in the peritoneum and are subsequently cleared by the immune system. The found hormone receptor status with a predominance of PR over ER of these lesions also supports this theory.

Concerning the causality of the inflammatory changes in the peritoneal tissue of women with EM, further research is required to be able to offer patients better and long-term successful therapeutic options.

\section{References}

1. Laschke MW, Menger MD (2016) The gut microbiota: a puppet master in the pathogenesis of endometriosis? Am J Obstet Gynecol 215: e1-4. [crossref]

2. O DF, Roskams T, Van den Eynde K, Vanhie A, Peterse DP, et al. (2016) The Presence of Endometrial Cells in Peritoneal Fluid of Women With and Without Endometriosis. Reprod Sci 24: 242-251. [crossref]

3. Barcena de Arellano ML, Gericke J, Reichelt U, Okuducu AF, Ebert AD, et al. (2011) Immunohistochemical characterization of endometriosis-associated smooth muscle cells in human peritoneal endometriotic lesions. Hum Reprod 26: 2721-2730. [crossref]

4. Fukunaga M (2000) Smooth muscle metaplasia in ovarian endometriosis. Histopathology 36: 348-352. [crossref]

5. Prevalence and anatomical distribution of endometriosis in women with selected gynaecological conditions: results from a multicentric Italian study. Gruppo italiano per lo studio dellendometriosi. Hum Reprod 9: 1158-1162. [crossref]

6. Imesch P, Fink D (2016) [Endometriosis Update 2016]. Praxis (Bern 1994) 105: 253257. [crossref]

7. Rizner TL (2015) Diagnostic potential of peritoneal fluid biomarkers of endometriosis. Expert Rev Mol Diagn 15: 557-580. [crossref]

8. Kavoussi SK, Lim CS, Skinner BD, Lebovic DI, As-Sanie S (2016) New paradigms in the diagnosis and management of endometriosis. Curr Opin Obstet Gynecol 28: 267-276. [crossref]

9. Burney RO, Giudice LC (2012) Pathogenesis and pathophysiology of endometriosis. Fertil Steril 98: 511-519. [crossref] 
10. Wanyonyi SZ, Sequeira E, Mukono SG (2011) Correlation between laparoscopic and histopathologic diagnosis of endometriosis. Int J Gynaecol Obstet 115: 273-276. [crossref]

11. Practice Committee of the American Society for Reproductive, M., Treatment of pelvic pain associated with endometriosis: a committee opinion. Fertil Steril 101: 927-935. [crossref]

12. Giudice LC, Kao LC (2004) Endometriosis. Lancet 364: 1789-1799.

13. Levy AD, Shaw JC, Sobin LH (2009) Secondary tumors and tumorlike lesions of the peritoneal cavity: imaging features with pathologic correlation. Radiographics 29: 347-373. [crossref]

14. Meyers MA (1973) Distribution of intra-abdominal malignant seeding: dependency on dynamics of flow of ascitic fluid. Am J Roentgenol Radium Ther Nucl Med 119: 198-206. [crossref]

15. Hopton EN, Redwine DB (2014) Eyes wide shut: the illusory tale of 'occult' microscopic endometriosis. Hum Reprod 29: 384-387. [crossref]

16. Murphy AA, Green WR, Bobbie D, dela Cruz ZC, Rock JA (1986) Unsuspected endometriosis documented by scanning electron microscopy in visually normal peritoneum. Fertil Steril 46: 522-524. [crossref]

17. Redwine DB (1988) Is "microscopic" peritoneal endometriosis invisible? Fertil Steril 50: 665-666. [crossref]

18. Redwine DB, Yocom LB (1990) A serial section study of visually normal pelvic peritoneum in patients with endometriosis. Fertil Steril 54: 648-651. [crossref]

19. Nisolle M, Paindaveine B, Bourdon A, Berlière M, Casanas-Roux F, et al. (1990) Histologic study of peritoneal endometriosis in infertile women. Fertil Steril 53: 984988. [crossref]

20. Nezhat F, Allan CJ, Nezhat C, Martin DC (1991) Nonvisualized endometriosis at laparoscopy. Int J Fertil 36: 340-343. [crossref]

21. Balasch J, Creus M, Fábregues F, Carmona F, Ordi J, et al. (1996) Visible and nonvisible endometriosis at laparoscopy in fertile and infertile women and in patients with chronic pelvic pain: a prospective study. Hum Reprod 11: 387-391. [crossref]

22. Khan $\mathrm{KN}$, et al. (2014) Occult microscopic endometriosis: undetectable by laparoscopy in normal peritoneum. Hum Reprod 29: 462-472.
23. Chiantera V, Dessole M, Petrillo M, Lucidi A, Frangini S, et al. (2016) Laparoscopic En Bloc Right Diaphragmatic Peritonectomy for Diaphragmatic Endometriosis According to the Sugarbaker Technique. J Minim Invasive Gynecol 23: 198-205. [crossref]

24. Vlek SL, et al. (2016) Laparoscopic Imaging Techniques in Endometriosis Therapy: A Systematic Review. J Minim Invasive Gynecol 23: 886-892.

25. Zhu L, Lier MC, Ankersmit M, Ket JC, Dekker JJ, et al. (2019) Comparisons of the efficacy and recurrence of adenomyomectomy for severe uterine diffuse adenomyosis via laparotomy versus laparoscopy: a long-term result in a single institution. J Pain Res 12: 1917-1924. [crossref]

26. Bricou A, Batt RE, Chapron C (2008) Peritoneal fluid flow influences anatomical distribution of endometriotic lesions: why Sampson seems to be right. Eur J Obstet Gynecol Reprod Biol 138: 127-134. [crossref]

27. Koninckx PR, Kennedy SH, Barlow DH (1998) Endometriotic disease: the role of peritoneal fluid. Hum Reprod Update 4: 741-751. [crossref]

28. Sasson IE, Taylor HS (2008) Stem cells and the pathogenesis of endometriosis. Ann N Y Acad Sci 1127: 106-115. [crossref]

29. Gazvani R, Templeton A (2002) Peritoneal environment, cytokines and angiogenesis in the pathophysiology of endometriosis. Reproduction 123: 217-226. [crossref]

30. Scheerer C, Bauer P, Chiantera V, Sehouli J, Kaufmann A, et al. (2016) Characterization of endometriosis- associated immune cell infiltrates (EMaICI). Arch Gynecol Obstet 294: 657-664. [crossref]

31. Lindsay SF, Luciano DE, Luciano AA (2015) Emerging therapy for endometriosis. Expert Opin Emerg Drugs 20: 449-461. [crossref]

32. Schweppe KW (2005) [Guidelines for the use of GnRH-analogues in the treatment of endometriosis]. Zentralbl Gynakol 127: 308-313. [crossref]

33. Liu S, Xin X, Hua T, Shi R, Chi S, et al. (2016) Efficacy of Anti-VEGF/VEGFR Agents on Animal Models of Endometriosis: A Systematic Review and Meta-Analysis. PLoS One 11: e0166658. [crossref]

34. Burney RO, Giudice LC (2012) Pathogenesis and pathophysiology of endometriosis. Fertil Steril 98: 511-519. [crossref] 